\title{
Physical Activity and Healthcare Costs: Projections for Poland in the Context of an Ageing Population
}

\author{
Małgorzata Kalbarczyk ${ }^{1}$ (D) · Joanna Mackiewicz-Łyziak ${ }^{1}$ (D)
}

Published online: 28 March 2019

(c) The Author(s) 2019

\begin{abstract}
Background The proportion of older people in many countries, including Poland, is expected to increase, which will lead to a rise in healthcare costs.

Objectives This study aims to analyse the impact of older adults' physical activity on public spending on healthcare in Poland over the long term.

Method To include the physical activity factor needed for our long-term projections, we modified the macro-simulation model used by the European Commission in Poland. We used the Survey of Health, Ageing and Retirement in Europe database to calculate the number of healthcare users depending on their level of physical activity. We used three measures of healthcare users: people with chronic diseases, people who were in hospital or visited a doctor more than once in the previous year, and people who subjectively evaluated their health as fair or poor.

Results We found that a higher level of physical activity in older adults is associated with lower public expenditure on healthcare for all measures adopted. However, the magnitude of this effect differed depending on the measure used, with gains ranging from 0.4 to $1.2 \%$ of gross domestic product per year by the end of the projection horizon.

Conclusion Our findings provide a strong argument for social policy in Poland to intensify the promotion of physical activity in society to decrease future healthcare costs of older adults.
\end{abstract}

\section{Key Points for Decision Makers}

Physical activity by older people as a health-enhancing factor may reduce the future cost of healthcare resulting from population ageing.

Our calculations suggest that the gains from the increase of physical activity of older people may range from 0.4 to $1.2 \%$ of gross domestic product per year by the end of the projection horizon (i.e. year 2060), depending on the assumptions used.

As Polish seniors are characterized by a relatively low level of physical activity, behavior-changing policies have the potential to decrease future health care cost.

Małgorzata Kalbarczyk

mkalbarczyk@wne.uw.edu.pl

1 Faculty of Economic Sciences, University of Warsaw, ul. Dluga 44/50, Warsaw, Poland

\section{Introduction}

The percentage of people aged $\geq 80$ years is expected to increase from 5.6\% in 2018 to $>12 \%$ in 2060 across EU countries (Eurostat population projection 2015). Life expectancy is increasing while birth rates are declining, resulting in population ageing. Ageing is associated with a higher risk of chronic diseases, mild disability, and cognitive decline [1, 2]. Moreover, a higher percentage of the oldest individuals will experience 'an epidemic of chronic disease' [3]. This will increase the need for medical and social services as well as compound related challenges for social policy.

An ageing population in many parts of the world raises concerns about the sustainability of public finances in the context of increasing healthcare and long-term care (LTC) expenditures. The costs of healthcare and LTC are increasing as a share of gross domestic product (GDP) owing to an ageing population in Europe. This is because the expenditure per capita on healthcare increases with a person's age, particularly starting from 55 years for men and 60 years for women [4]. Therefore, an increase in the population 
percentage of older people should lead to an increase in overall spending on healthcare services in relation to GDP.

However, it should be noted that the link between population ageing and the level of healthcare costs might be more complicated. Some studies suggest that an increase in the percentage of older people in the population will not necessarily translate into significantly higher healthcare expenditures $[5,6]$. One factor that could significantly affect healthcare costs, but is usually not considered in long-term projections, is technological progress. Improved medical technology could effectively dampen the increase in healthcare expenditures caused by population ageing. However, Rechel et al. [6] found that population ageing challenges healthcare systems with the increase in the proportion of people with multimorbidity and chronic diseases. Overall, the common view, supported by long-term projections, is that population ageing leads to an increase in healthcare expenditures.

Thus, the question is how social policy can respond to changes in healthcare expenditures associated with population ageing. One of a few broadly (i.e. across all stakeholder groups) acceptable policy options are lifestyle modifications [7]. All activities that ensure better health in old age should potentially decrease healthcare expenditures. One of the factors that contributes to healthy ageing is physical activity, and the positive impact of physical activity on health seems to be well-established in the literature. Physical activity has been found to be related to a lower risk of several diseases, including cardiovascular diseases, type 2 diabetes mellitus, osteoarthritis, some types of cancer, dementia, and depression $[1,2,8,9]$. In a comprehensive survey of studies, Warburton et al. [10] confirmed that low physical activity increases the risk of several chronic diseases and found that the idea of health benefits resulting from increased physical activity is consistent across the literature. This confirmed impact of physical activity on health status may lead to the conclusion that if higher physical activity leads to better health, it should also lead to lower healthcare costs. This idea was discussed by Rechel et al. [6], who argued that active ageing will postpone healthcare expenditures.

In addition, several other studies have directly investigated the impact of physical activity on healthcare costs. Andreyeva and Sturm [11] found that, among American adults aged 54-69 years, a lack of regular physical activity was associated with an average $7 \%$ increase in overall healthcare costs over 2 years. In Canada, Katzmarzyk et al. [12], Katzmarzyk and Janssen [13] and Janssen [14] assessed the costs of physical inactivity. Their results ranged from 2.5 to $3.8 \%$ of total healthcare costs. Maresova [15] obtained estimates of different magnitudes for the Czech Republic; according to her results, the costs of physical inactivity were equal to $0.4 \%$ of total healthcare costs. Dallmeyer et al. [16] estimated the costs of inactivity in the context of population ageing in Germany and is the only study to address physical inactivity and population ageing together. To do so, they estimated the proportion of a given disease that could be attributed to physical inactivity for five selected diseases and accordingly calculated the total costs of inactivity. Based on population projections, they projected the costs per capita until 2060. They found that these costs are expected to increase only for those aged $\geq 65$ years, but the magnitude of the increase would be as high as $50 \%$.

Although these studies generally confirm that physical inactivity is associated with higher healthcare costs, there are few studies on the subject. Moreover, they use different methods, and their estimates vary in terms of magnitudes. Therefore, there is still room for further research as the existing evidence is not clear cut.

Our contribution to the literature may be summarised as follows. First, unlike most studies, we attempted to estimate the effect of physical activity on healthcare spending over a long-term period; our projections are made until 2060. In this respect, our study is similar only to that by Dallmeyer et al. [16]. Like in their study, we jointly analysed the effects of population ageing and the physical activity of older people on healthcare costs, but we took a different approach. First, rather than estimating the costs of inactivity, we projected public healthcare expenditures using three different assumptions regarding the level of physical activity performed by older adults: vigorous activity, moderate activity, and inactivity. This allowed us to compare the healthcare costs for different levels of activity assumed. Therefore, we present different simulations of public spending on healthcare (as a percentage of GDP) depending on the level of physical activity while simultaneously capturing the effect of population ageing. Second, instead of focusing on selected diseases, we proposed three measures of healthcare users' health status: people with chronic diseases, people who were in hospital or visited a doctor more than once in the previous year, and people who subjectively evaluated their health as fair or poor. For these three measures, we performed separate simulations of healthcare costs depending on the assumed level of older people's physical activity, which allowed us to check the robustness of our results.

We conducted this study using data for older people in Poland. According to the European Commission's (EC's) long-term projections [4], the costs of Poland's ageing population are mostly associated with the increase in public spending on healthcare and LTC, whereas public pensions are projected to stay at similar levels (as a percentage of GDP). In this respect, Poland's situation differs from most other European countries where the primary burden relates to an increase in pensions. Therefore, Poland may be among the countries with the potential to benefit most from promoting physical activity in its society. 
Fig. 1 Schematic presentation of European Commission projection methodology. Source: European Commission. AWG

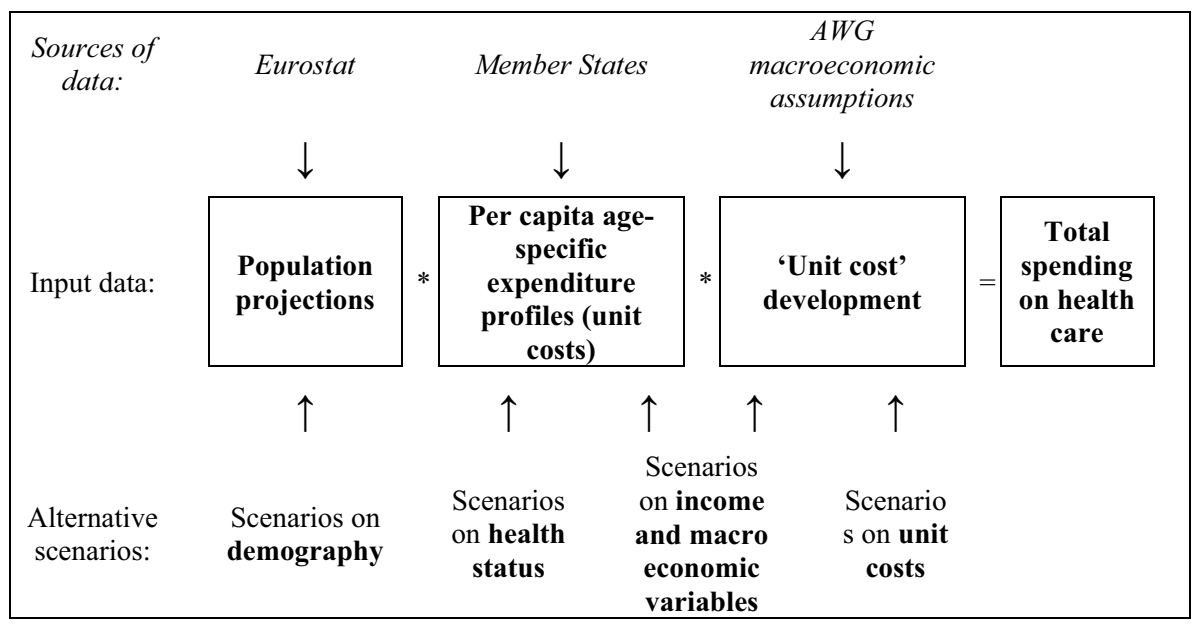

\section{Materials and Methods}

\subsection{Data}

The data used in this study are from the Survey of Health, Ageing and Retirement in Europe (SHARE) database. It is a biannual panel study conducted on a representative sample of people aged $\geq 50$ years across 20 countries, including Poland [17]. The study concerns the health, economic, and social situation of individuals, and the data contain information regarding respondents' health, functional capacity, and physical activity at moderate and vigorous levels as declared by the respondents. Six waves of data were available as of May 2018. Poland joined SHARE in the second wave in 2006, and data for Poland were collected in four waves of the panel. In this paper, we used only Release 6.1 .1 of Wave 4 of the survey, which was conducted in 2011-2013. These years are the closest to the period included in the EC's report. The sample includes 1733 Poles ( 1677 were aged $>55$ years).

The population projections used in the present study come from the Eurostat database (EUROPOP). Forecasts of GDP per capita up to 2060, as well as healthcare public expenditures in each age and sex group in the base year (in this case, the original source of data is the Polish National Health Fund) were provided by the EC.

\subsection{The European Commission's Macro-Simulation Model}

To project future healthcare costs of older people, depending on various scenarios of their physical activity level, we used the EC's macro-simulation model to project public expenditures related to ageing published in the Ageing Reports. The procedure is described in detail in The 2015 Ageing Report [18]. In this model, the overall population is divided into groups according to age and sex. The EC uses the
EUROPOP data for forecasting the future numbers of each age and sex group. The projection is made up to 2060 . The calculation method of predicted future healthcare costs is very simple: the member states provide profiles of age- and sex-specific per capita public expenditures on healthcare in a base year. In the case of our exercise, the base year is $2012 .{ }^{1}$ The per capita cost is assumed to change over time according to certain macroeconomic variables (i.e. forecasted growth rate of GDP per capita). Such projected cost per capita is multiplied by the projected population size of each age and sex group. The sum of healthcare expenditures for all groups constitutes the projected total public expenditure on healthcare. Figure 1 presents the procedure.

The EC uses several different scenarios to estimate the impact of different determinants on healthcare costs. In this sense, the projections should not be treated as forecasts but as simulations that try to isolate the effect of every respective factor on healthcare expenditure. The basic scenario is the 'demographic scenario' that estimates the effect of an ageing population on healthcare costs. It assumes no change in government health policy, age/sex-specific morbidity rates, and provision of healthcare services. Life expectancy increases as in the underlying population projection, but the number of years spent in good health remains constant. The healthcare cost per capita is assumed to change in line with GDP per capita. These assumptions mean that every change in the public expenditure share of healthcare in GDP is due to a change in the population age structure.

\footnotetext{
1 A new Ageing Report was published in May 2018, but the data used in this report were not available at the time of making calculations for this study.
} 
Fig. 2 Schematic presentation of modified projection methodology. Source: Authors' preparation. AWG

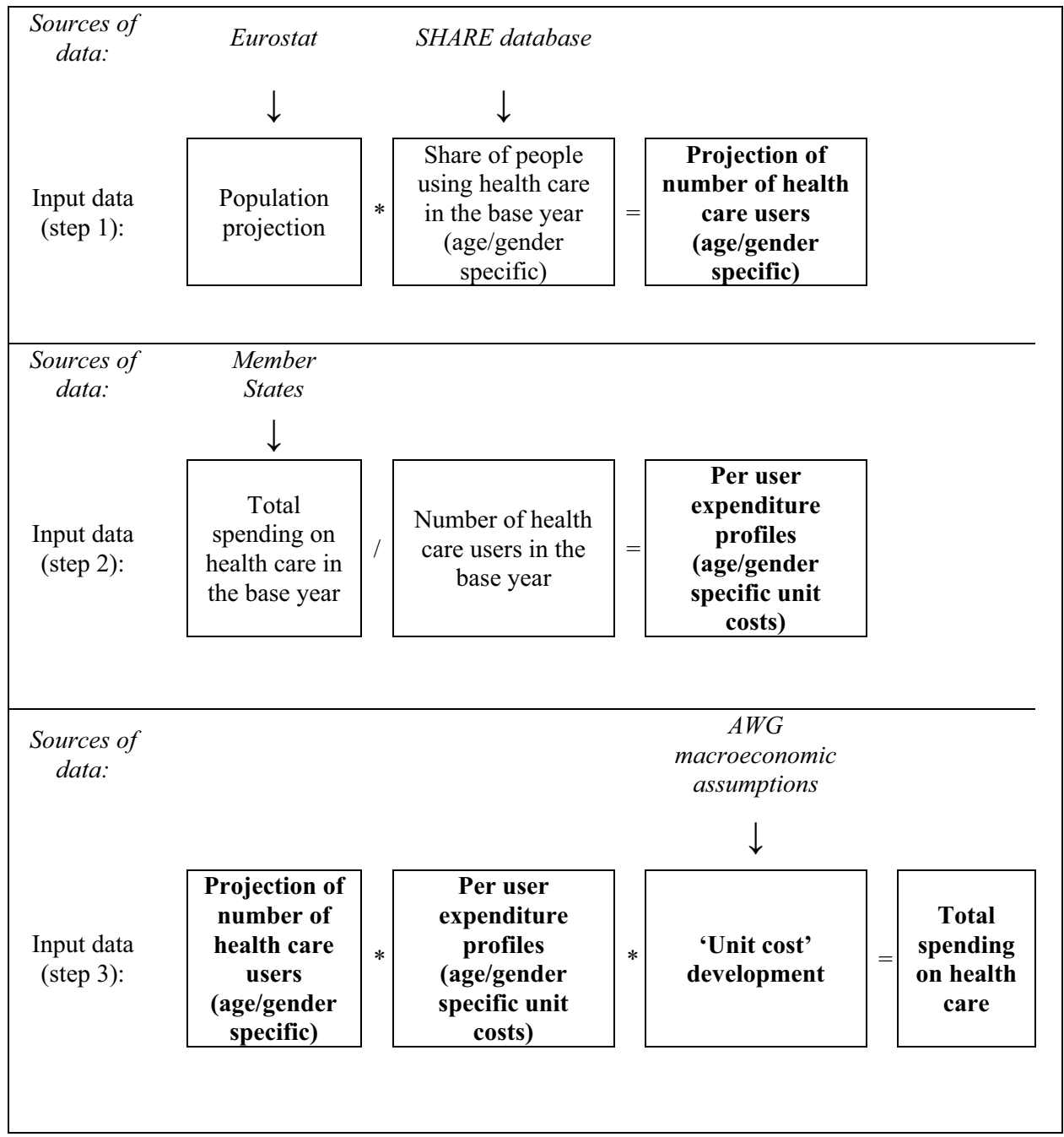

\subsection{Method}

While performing our simulations, we treated the demographic scenario as the baseline case. However, we changed the method to calculate the cost per user instead of the cost per capita (the difference in the method is depicted in Figs. 1, 2). The method used by the EC implicitly assumes that the whole population uses healthcare, therefore the category of cost used is cost per capita. Not changing the total costs in the baseline scenario, we used the category of healthcare cost per user: total costs divided by the number of healthcare users in each sex/age group. This allowed us to differentiate the number of healthcare users depending on the level of physical activity performed.

Estimating the number of healthcare users is not straightforward. Using the SHARE database, we designated groups benefiting from healthcare three different ways. The first way was to calculate the percentage of people with at least one chronic disease based on the fact that, for example, threequarters of health expenditures in the USA are currently related to chronic diseases [3]. The second way was to calculate the percentage of people who subjectively evaluated their health as fair or poor. The question was posed as follows: 'Would you say your health is (1) excellent, (2) very good, (3) good, (4) fair, or (5) poor?' Respondents who rated their health as 'fair' or 'poor' were marked as healthcare users. The third way was to enumerate the percentage of people who were in hospital in the previous year or had visited a doctor more than once. For these three measures of health status, we calculated healthcare cost per user by dividing total costs (provided by Polish National Health Fund) by the number of users in each age/sex group in the base year. Assuming that the percentage of healthcare users would not change over time and the cost per user would evolve in line with GDP per capita, we projected healthcare expenditures until 2060. The result is analogous with the EC method and shows the isolated (predicted) effect of an ageing population on healthcare expenditures over time. However, calculating the healthcare costs in this manner enabled us to estimate 
the impact of the physical activity of older people on the healthcare costs as described in the following.

At this point, it is worth stressing that our analysis includes only people aged $\geq 55$ years, first because the SHARE database covers only people aged $\geq 50$, and second, because we were interested only in the impact of an ageing population and older people's physical activity levels on public healthcare expenditure. Because the percentage of observation in the group aged 50-55 years was very low, we decided to eliminate this group from the sample. Therefore, the estimated future costs of healthcare include only public spending on people aged $\geq 55$ years.

To verify how physical activity influences healthcare costs, we considered two questions regarding the physical activity of respondents from the SHARE database. The first concerned vigorous activity: "How often do you engage in vigorous physical activity, such as sports, heavy housework, or a job that involves physical labour?" The second concerned moderate activity: "How often do you engage in activities that require a moderate level of energy, such as gardening, cleaning the car, or taking a walk?"2 Respondents answered based on a 4-point scale: (1) more than once a week, (2) once a week, (3) one to three times a month, and (4) hardly ever or never. For each question, we aggregated answers into two categories: (1) as 'active' individuals, meaning those who were active at least once a week, and (2) as 'inactive' individuals, meaning those who engaged in physical activity less than once a week.

In the next step of the analysis, we compared the EC baseline projection with expenditure projections made for three hypothetical situations: all the population aged $\geq 55$ years is vigorously active, moderately active, or inactive (not active even at a moderate level). To make projections, we calculated the proportion of people using healthcare (for three different definitions of healthcare users) separately for the vigorously active, moderately active, and inactive groups. For all the scenarios, the projections were prepared according to the procedure presented in Fig. 2. For example, using the number of people with chronic diseases as a measure of healthcare users, we calculated the percentage of healthcare users in the vigorously active, moderately active, and inactive groups in the base year. Multiplying these percentages by population projection for each age/sex group, we obtained the projected number of healthcare users for each level of physical activity. Projected number of healthcare users multiplied by the expenditure per user produced the total healthcare expenditure in each year. The procedure was repeated for the two other definitions of healthcare users (those with
Table 1 Summary statistics of SHARE sample for Poland. Source: Authors' calculations based on SHARE database wave 4 release 6.1.0

\begin{tabular}{|c|c|c|c|}
\hline Variable & Male & Female & Total \\
\hline \multicolumn{4}{|c|}{ One or more chronic diseases (\%) } \\
\hline $55-60$ & 69.01 & 71.00 & 70.15 \\
\hline $60-65$ & 73.48 & 78.79 & 76.46 \\
\hline $65-70$ & 80.99 & 87.59 & 84.23 \\
\hline $70-75$ & 84.04 & 95.08 & 90.28 \\
\hline $75-80$ & 87.34 & 89.16 & 88.27 \\
\hline$\geq 80$ & 81.93 & 92.37 & 88.06 \\
\hline \multicolumn{4}{|c|}{ Hospital or visit to a doctor more than once in last year (\%) } \\
\hline $55-60$ & 63.37 & 74.03 & 69.48 \\
\hline $60-65$ & 79.44 & 80.60 & 80.10 \\
\hline $65-70$ & 75.18 & 86.03 & 80.51 \\
\hline $70-75$ & 84.04 & 86.89 & 85.65 \\
\hline $75-80$ & 87.18 & 81.93 & 84.47 \\
\hline$\geq 80$ & 71.95 & 73.73 & 73.00 \\
\hline \multicolumn{4}{|c|}{ Fair or poor subjective health (\%) } \\
\hline $55-60$ & 43.02 & 43.29 & 43.18 \\
\hline $60-65$ & 47.51 & 48.92 & 48.30 \\
\hline $65-70$ & 54.93 & 58.09 & 56.47 \\
\hline $70-75$ & 70.21 & 77.05 & 74.07 \\
\hline $75-80$ & 70.89 & 79.52 & 75.31 \\
\hline$\geq 80$ & 75.90 & 84.75 & 81.09 \\
\hline $\begin{array}{l}\text { Vigorously active once a } \\
\text { week or more }(\%)\end{array}$ & 36.35 & 25.92 & 30.46 \\
\hline $\begin{array}{l}\text { Moderately active once a } \\
\text { week or more }(\%)\end{array}$ & 34.18 & 37.09 & 35.82 \\
\hline Observations $(N)$ & 755 & 978 & 1733 \\
\hline
\end{tabular}

SHARE Survey of Health, Ageing and Retirement in Europe

a subjective evaluation of health as 'fair' or 'poor' and those who were in hospital or had multiple doctor visits in the previous year). We considered 'vigorously active' and 'inactive' scenarios as two extreme cases that set the boundaries for the level of public expenditures on healthcare.

Analysing the relationship between physical activity and health may involve the problem of causality: it is difficult to determine whether physical activity affects health or if already existing health problems affect people's physical activity. This problem may be solved using the Granger causality test, which enables us to investigate causality between two variables, particularly if one variable precedes another. We tested for Granger causality in the panel data for each measure of health status (chronic disease incidence, subjective health evaluation, and hospital or doctor visit) and physical activity (vigorous and moderate).

\footnotetext{
${ }^{2}$ We distinguished moderate from vigorous physical activity, assuming that even moderate-intensity physical activity done once a week has a health-enhancing effect.
} 
Fig. 3 Healthcare costs as a percentage of gross domestic product for Poland for the period 2013-2060 (chronic diseases as a measure of healthcare users). Source: Authors' calculations based on the European Commission's and SHARE (Survey of Health, Ageing and Retirement in Europe) data

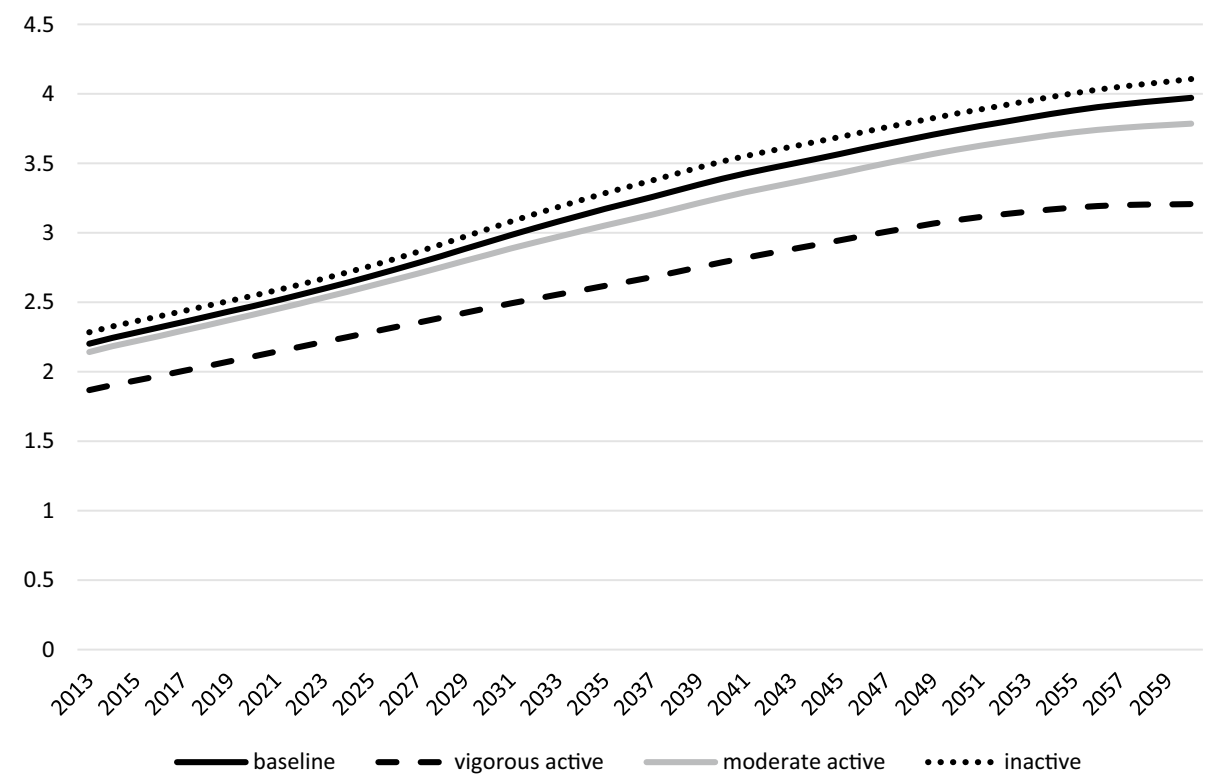

\section{Results}

Table 1 presents the descriptive statistics of the sample. We observed that men were more often vigorously active than women, but, in general, about $30 \%$ of Poles were vigorously active. ${ }^{3}$ Women in Poland were more moderately active than vigorously active, and the percentage for moderate activity was higher for women than men. We can also perceive the percentage of healthcare users according to the three measures of health status. The highest differentiation was for healthcare users who subjectively evaluated their health as fair or poor. Here, there was also a negative correlation between age and subjective health valuation. In the other two measures, dispersion was lower, and the percentage of healthcare users was more stable across age groups.

Figure 3 presents the results on healthcare costs with chronic disease incidence as a measure of healthcare users. For the baseline scenario, in 2060, healthcare expenditures will be nearly $4 \%$ of GDP. In all scenarios, we observed an increase in healthcare expenditures in relation to GDP. However, there are important differences between the respective scenarios. In 2060, healthcare expenditures will increase to $4.1 \%$ of GDP for the inactive scenario but to only $3.2 \%$ of GDP for the vigorously active scenario.

Similar results can be observed in Fig. 4, for which hospitalization or visit to a doctor more than once was taken as a

\footnotetext{
3 This percentage was slightly lower than that found in other studies on physical activity by older people in Poland (e.g. Rowinski and Dabrowski [20] and GUS [21]). The differences may result from different questions concerning the level of physical activity in the questionnaire.
}

measure of healthcare users. However, the simulated values of healthcare costs as a percentage of GDP are higher for the vigorously active scenario compared with Fig. 1 (2.04\% and $3.61 \%$ in 2013 and 2060, respectively). The differences in simulations of healthcare expenditures for an inactive scenario are negligible.

The last variant uses a subjective measure of health status of healthcare users (Fig. 5). In this case, we also noticed an increase in healthcare expenditures in relation to GDP for the analysed period. However, for this measure of healthcare users, the scenarios differ to a larger degree from each other than in the case of the other measures. For the vigorously active and inactive scenarios, healthcare expenditures amounted to $2.79 \%$ and $4.43 \%$ of GDP in 2060, respectively.

Finally, as mentioned in the Methods, we verified causality between physical activity and health status using the Granger causality test for the panel data. The SHARE as a panel database allows such analysis to determine whether any change in health affects physical activity or vice versa. Table 2 presents the results, which confirm that none of the three measures of health status Granger-cause physical activity, whereas moderate physical activity Granger-causes health status measured by chronic disease incidence and hospital or doctor visit. Vigorous activity was also found to Granger-cause health status measured by chronic disease incidence. For health measured by subjective health status, we did not observe Granger causality.

Our results confirm the results of many previous studies $[1,2,8-10,19]$ that physical activity determines health status and not vice versa. However, as our panel consisted of only three waves (three observations for each respondent), the results of formal tests such as the Granger causality test could be doubtful. 
Fig. 4 Healthcare costs as a percentage of gross domestic product for Poland for the period 2013-2060 (hospital or visit to a doctor more than once as a measure of healthcare users). Source: Authors' calculations based on the European Commission's and SHARE (Survey of Health, Ageing and Retirement in Europe) data

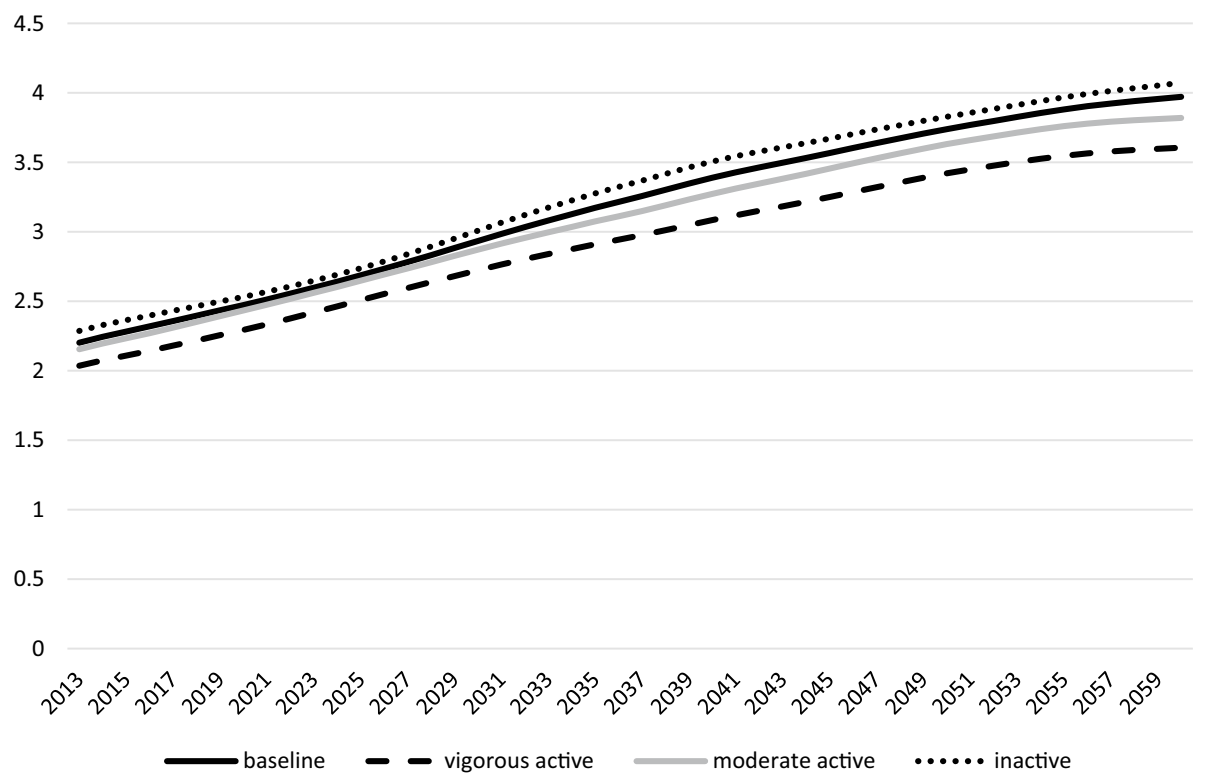

Fig. 5 Healthcare costs as a percentage of gross domestic product for Poland for the period 2013-2060 (subjective measure of healthcare users). Source: Authors' calculations based on the European Commission's and SHARE (Survey of Health, Ageing and Retirement in Europe) data

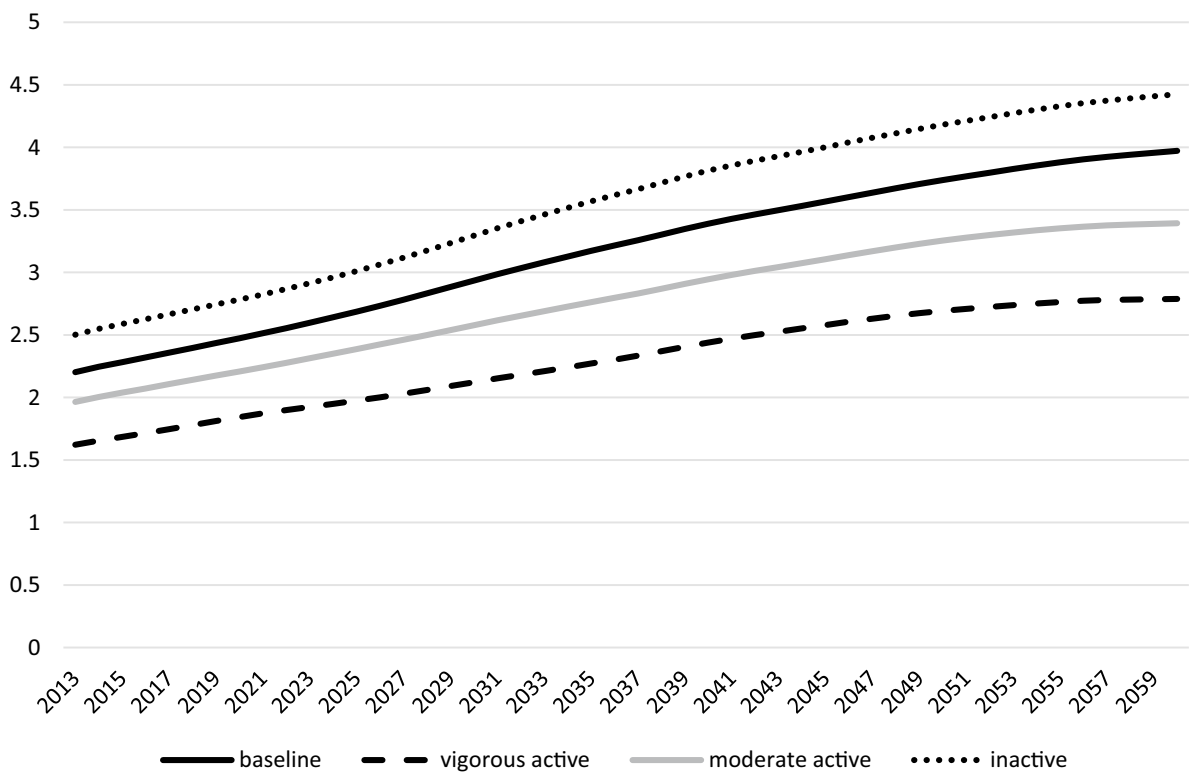

Table 2 Results of Granger causality test $\left(\chi^{2}\right.$ statistics and $p$ values). Source: Authors' calculation on SHARE database wave 4 release 6.1 .0

\begin{tabular}{|c|c|c|c|c|}
\hline & \multicolumn{2}{|c|}{ Physical activity Granger-cause health } & \multicolumn{2}{|c|}{ Health Granger-cause physical activity } \\
\hline & Moderately active & Vigorously active & Moderately active & Vigorously active \\
\hline One or more chronic diseases & $6.71(0.01)$ & $5.25(0.02)$ & $0.57(0.45)$ & $0.26(0.61)$ \\
\hline $\begin{array}{l}\text { Hospital or visit to a doctor more than } \\
\text { once in last year }\end{array}$ & $4.73(0.03)$ & $0.73(0.39)$ & $0.48(0.49)$ & $0.19(0.66)$ \\
\hline Fair or poor subjective health & $0.87(0.35)$ & $0.69(0.41)$ & $0.24(0.63)$ & $0.67(0.41)$ \\
\hline
\end{tabular}

Values in parentheses are $p$ values

SHARE Survey of Health, Ageing and Retirement in Europe 


\section{Discussion}

In this study, we analysed the impact of older adults' physical activity on the projected levels of healthcare expenditures. In general, our findings suggest that a higher level of physical activity leads to lower healthcare costs. Moreover, the potential gains from a higher physical activity level increase over time. However, we observed some differences in the levels of projected costs among different measures of healthcare users. In general, our results confirm the results of other empirical studies estimating the healthcare costs of inactivity $[13,15,16]$. These studies show that physical inactivity increases healthcare costs. However, in quantitative terms, our results are not comparable with their findings because of the different aims, assumptions, and methods used by the studies.

We observe the least difference between vigorously active and inactive scenarios from 2013 to 2060 for hospitalization or multiple doctor visits as a measure of healthcare users (0.25\% GDP and $0.46 \%$ GDP in 2013 and 2060, respectively). The advantage of this measure is its objectivity; however, even though we include people with at least two doctor visits, this measure still contains people who are healthy and whose two doctor visits have a relatively low cost in terms of healthcare costs. This may explain why the differences between vigorously active and inactive for this measure are the lowest.

The largest difference was found for the subjective health status measure (0.88\% GDP and 1.64\% GDP in 2013 and 2060 , respectively). Those who are vigorously active more often evaluate their health status better than those who are inactive and are possibly less likely to use healthcare than are inactive individuals. However, the subjective nature of this measure could mean the real healthcare costs of vigorously active individuals are underestimated. For chronic disease incidence as a measure of healthcare users, healthcare cost projections are midway between the other two variants $(0.41 \%$ GDP and $0.91 \%$ GDP in 2013 and 2060, respectively). Therefore, the healthcare cost projection as a percentage of GDP can be estimated in a range determined by different measures.

Our study has certain strengths. Its main strength is that we estimate the effect of physical activity of older people on healthcare costs using a long-term projection, until 2060. Additionally, to the best of our knowledge, this is the first study that projects healthcare expenditures in relation to different levels of physical activity. Furthermore, unlike other studies focusing only on selected diseases, we used three different measures of the number of healthcare users, which allows us to assess the robustness of our results.

Undoubtedly, our research also has some limitations. The first concerns the definition of the level of physical activity.
According to a World Health Organization recommendation [22], people aged $>65$ years should perform either at least 150 min of moderate-intensity physical activity throughout the week or at least $75 \mathrm{~min}$ of vigorous-intensity activity throughout the week or an equivalent combination of moderate- and vigorous-intensity activity. Unfortunately, the SHARE database does not provide such precise data on the duration and frequency of physical activity. In our study, we define respondents as active if they were active at least once a week, which may be less than the recommended level. However, even for this level of physical activity, the projected gains range from 0.4 to $1.2 \%$ of GDP (depending on the measure of healthcare users) per year by the end of the projection horizon. Estimations defining active respondents as those who are active more than once a week (which was the most detailed information about physical activity frequency provided by the SHARE database) show a slight increase in cost savings, which range from 0.4 to $1.6 \%$ of GDP (data not shown). These results suggest that the higher the assumed level of physical activity, the larger the reduction of healthcare cost.

Second, it is also worth remembering that the SHARE database only provides information on self-reported physical activity. This could lead to some inaccuracies regarding the declaring of the physical activity level and the distinguishing between moderate and vigorous levels of activity reported by respondents.

Third, we calculated projected paths of healthcare expenditures for different levels of physical activity. These should be treated as hypothetical scenarios that merely present the boundaries of how these expenditures could develop in the future. The occurrence of the two extreme scenarios exactly as presented is rather unlikely. However, whether future healthcare expenditures will be closer to the higher or lower boundary depends on the behaviour of the population and the effectiveness of policy aimed at promoting physical activity.

Our findings provide a strong argument for social policy in Poland to intensify the promotion of physical activity in society to decrease the future healthcare costs of older adults. The need for the promotion of physical activity and the effectiveness of such programmes has been stressed by other researchers, for example Bopp and Fallon [23]. It seems that, in Poland, there is much room for improvement in this field. According to the SHARE database, Poland occupies the second-worst position among SHARE countries with respect to older adults' level of physical activity. Therefore, the promotion of physical activity may significantly improve the health of Polish seniors and reduce healthcare expenditures in the future.

Existing studies show that Polish seniors have difficulty implementing physical activity at an older age, as they lack such habits [24]. This is one of the most important barriers 
to an active lifestyle for older people in Poland. Moreover, Polish seniors claim that the lack of information about recommended activities for their diseases results in inactivity. Therefore, important policy tasks are to help Polish seniors create habits that promote an active lifestyle and to adapt existing programmes to fit the special needs of seniors with different disabilities. In general, the literature stresses the need for individualised programmes and goal setting in changing older adults' physical activity behaviour [25, 26].

\section{Conclusion}

We analysed the impact of older adults' physical activity on healthcare public spending in Poland over a long-term period. We jointly assessed the effect of an ageing population and the physical activity of older members of society. To include the physical activity factor in the long-term projections, we modified the EC's macro-simulation model for Poland and used the SHARE database to calculate the number of potential healthcare users by level of physical activity performed. To check the robustness of our results, we utilised three measures of healthcare users: people with chronic diseases, people who were in hospital or visited a doctor more than once in the previous year, and people who subjectively evaluated their health as fair or poor.

Our findings suggest that the public expenditures on healthcare of older people in Poland will consistently increase. Moreover, regardless of the measure used, these costs depend on assumed level of physical activity: vigorous, moderate, and inactivity. However, the differences among projections made for different activity levels depend on the estimation method of the number of healthcare users. Nevertheless, the gains from the increase of physical activity (the difference between the baseline scenario and the vigorous active scenario) may range from $0.4 \%$ (using the hospital or doctor visit measure) to $1.2 \%$ of GDP (using the subjective health status measure) per year at the end of the projection horizon. For the measure based on chronic disease incidence, this gain is estimated at $0.8 \%$ of GDP.

Polish seniors are characterised by a low level of physical activity compared with those in other European countries. This suggests the possibility exists to decrease future healthcare cost by improving the physical activity of the Polish society. For this aim, behaviour-changing policies should be applied.

Author Contributions The contribution of each author is 50\%. MK and JMŁ designed the study, conducted the fieldwork, analysed the data, and wrote the manuscript; both authors read, corrected, and approved the manuscript.

\section{Compliance with Ethical Standards}

Funding This study was funded by the National Science Centre Poland [UMO-2016/21/D/HS4/00691].

Conflict of interest Małgorzata Kalbarczyk and Joanna MackiewiczŁyziak have no conflicts of interest that are directly relevant to the content of this article.

Data Availability The datasets analysed during the current study are not publicly available because of restrictions imposed by the provider of the data (European Commission) but are available from the authors upon reasonable request and with permission of the European Commission.

Open Access This article is distributed under the terms of the Creative Commons Attribution-NonCommercial 4.0 International License (http://creativecommons.org/licenses/by-nc/4.0/), which permits any noncommercial use, distribution, and reproduction in any medium, provided you give appropriate credit to the original author(s) and the source, provide a link to the Creative Commons license, and indicate if changes were made.

\section{References}

1. Shuit AJ. Physical activity, body composition and healthy ageing. Sci Sports. 2006;21:209-13.

2. Rechel B, Doyle Y, Grundy E, McKee M. How can health systems respond to population ageing?. Copenhagen: World Health Organization on behalf of the European Observatory on Health Systems and Policies; 2009.

3. Dexter P, Douglas M, Clark D, Weiner M, Harris L, Livin L, Myers I, Shaw D, Blue L, Kunzer J, Overhage J. Preparing for an aging population and improving chronic disease management. AMIA Annu Symp Proced. 2010;2010:162-6.

4. European Commission. The 2018 Ageing Report. Economic and Budgetary Projections for the 28 EU Member States (2016-2070). Institutional Paper 079, May 2018.

5. Werblow A, Felder S, Zweifel P. Population aging and HC expenditure: a school of 'red herrings'? Health Econ. 2007;16:1109-26.

6. Rechel B, Grundy E, Robine J, Cylus J, Mackenbach J, Knai C, McKee M. Aging in the European Union. Lancet. 2013;381:1312-22.

7. Tordrup D, Angelis A, Kanavos P. Preferences on policy options for ensuring the financial sustainability of healthcare services in the future: results of a stakeholder survey. Appl Health Econ Health Policy. 2013;11(6):639-52.

8. Evans WJ, Cyr-Campell D. Nutrition, exercise, and healthy aging. J Am Diet Assoc. 1997;97:632-8.

9. World Health Organization. Global health risks-mortality and burden of disease attributable to selected major risks. Geneva: World Health Organization; 2009.

10. Warburton D, Charlesworth S, Ivey A, Nettlefold L, Bredin S. A systematic review of the evidence for Canada's physical activity guidelines for adults. Int J Behav Nutr Phys Act. 2010;2010:7-39.

11. Andreyeva T, Sturm R. Physical activity and changes in healthcare costs in late middle age. J Phys Act Health. 2006;3:S6-19.

12. Katzmarzyk PT, Gledhill N, Shephard RJ. The economic burden of physical inactivity in Canada. Can Med Assoc J. 2000;163(11):1435-40. 
13. Katzmarzyk PT, Janssen I. The economic costs associated with physical inactivity and obesity in Canada: an update. Can J Appl Physiol. 2004;29(1):90-115.

14. Janssen I. Healthcare costs of physical inactivity in Canadian adults. Appl Physiol Nutr Metab. 2012;37:803-6.

15. Maresova K. The costs of physical inactivity in the Czech Republic in 2008. J Phys Act Health. 2014;11(3):489-94.

16. Dallmeyer $\mathrm{S}$, Wicker $\mathrm{P}$, Breuer $\mathrm{C}$. How an aging society affects the economic costs of inactivity in Germany: empirical evidence and projections. Eur Rev Aging Phys Act. 2017;14:14-8.

17. Börsch-Supan A, Jürges H. The survey of health, ageing, and retirement in Europe. Mannheim: Mannheim Research Institute for the Economics of Aging, Methodology; 2005.

18. European Commission. The 2015 Ageing Report. Economic and Budgetary Projections for the 28 EU Member States (2013-2060). European Economy, 3/2015.

19. Rantanen T, Guralnik JM, Sakari-Rantala R, Leveille S, Simonsick EM, Ling S, Fried LP. Disability, physical activity, and muscle strength in older women: the women's health and aging study. Arch Phys Med Rehabil. 1999;80(2):130-5.

20. Rowinski R, Dabrowski A. Aktywnosc fizyczna Polaków w wieku podeszłym. In: Polsenior. Aspekty medyczne, psychologiczne, socjologiczne i ekonomiczne starzenia się ludzi w Polsce. Ed. Mossakowska M., Więcek A, Błędowski P. 2012; 531-548.
[Physical activity of elderly Poles. In: Polsenior. Medical, psychological, sociological and economic aspects of the aging of people in Poland].

21. GUS. Informacje i opracowania statystyczne: Uczestnictwo Polaków w sporcie i rekreacji ruchowej. 2009. Warszawa; 160. [Statistical information and studies: Participation of Poles in sport and physical recreation].

22. WHO. Global recommendations on physical activity for health. Switzerland: World Health Organisation; 2010.

23. Bopp M, Fallon E. Community-based interventions to promote increased physical activity. Appl Health Econ Health Policy. 2008;6:173-87.

24. Ministry of Sport and Tourism of the Republic of Poland. Badanie dotyczące uwarunkowań do podejmowania aktywności fizycznej przez osoby starsze w Polsce [A study on the conditions for physical activity by older people in Poland], December 2015.

25. Victor C, Rogers A, Woodcock A, Beighton C, Cook D, Kerry S, Iliffe S, Whincup P, Ussher M, Harris T. What factors support older people to increase their physical activity levels? An exploratory analysis of the experiences of PACE-Lift trial participants. Arch Gerantol Geriatr. 2016;67:1-6.

26. Brawley L, Rejeski J, King A. Promoting physical activity for older adults. The challenges for changing behaviour. Am J Prev Med. 2003;25:172-83. 